\title{
Utilização dos weblogs e de comunidades do orkut como ferramentas pedagógicas em cursos da área da saúde *
}

Fabio Maia ${ }^{1}$

Miriam Struchiner ${ }^{2}$

MAIA, F; STRUCHINER, M. The use of weblogs and orkut communities as pedagogical tools in courses in the health area. Interface - Comunic., Saude, Educ., v.14, n.35, p.905-18, out./dez. 2010.

This article discusses possibilities of the pedagogical use of Web 2.0 tools in courses in the health area. A research was conducted to identify weblogs and orkut communities that could be used as learning objects. Based on this material, a study was carried out with a group of Medical Psychology professors to examine their perceptions about the contributions of these tools to the development of pedagogical strategies. The results showed that these tools have the potential for being used as pedagogical resources. It was possible to identify different applications of these resources to Medical education as well as positive and negative aspects related to their use in the educational process. Finally, we concluded that the use of these tools favors the development of activities that value subjectivity in medical practice and allows new ways of putting students in contact with illness and patients' treatment experiences.

Keywords: Social software. Blogs. Educational technology. Medical education.
Este artigo discute as possibilidades de uso pedagógico das ferramentas da Web 2.0 em cursos da área da saúde. Foi realizada uma pesquisa para evidenciar a existência de weblogs e de comunidades do orkut que poderiam ser utilizadas como objetos de aprendizagem. A partir deste material, foi feito um estudo, com um grupo de professores da disciplina Psicologia Médica, para se analisarem as contribuições dessas ferramentas para o desenvolvimento de estratégias pedagógicas. Os resultados demonstraram que essas possuem potencial para serem utilizadas como recursos pedagógicos. Foi possível identificar diferentes propostas de seu uso na formação médica e os aspectos positivos e negativos relacionados à sua utilização no processo educacional. Por fim, concluiu-se que o uso dessas ferramentas favorece o desenvolvimento de atividades que valorizem a subjetividade na prática médica e permite novas formas de aproximação dos alunos com as experiências do adoecimento.

Palavras-chave: Software social. Blogs. Tecnologia educacional. Educação médica.
" Pesquisa submetida à apreciação do Comitê de Ética em Pesquisa em Seres Humanos. 1 Programa de Pós-Graduação em Educação em Ciências e Saúde, Núcleo de Tecnologia Educacional para Saúde, Universidade Federal do Rio de Janeiro (Nutes/UFRJ). Rua Gustavo de Andrade, 65. Vila da Penha, Rio de Janeiro, RJ, Brasil. 21.235-500. fabiomaiasouza@ terra.com.br ${ }^{2}$ Nutes/UFRJ. 


\section{Introdução}

Tradicionalmente, as práticas médicas têm como foco a dimensão sintomatológica dos quadros clínicos e a descrição dos elementos relacionados ao adoecimento, em que os aspectos subjetivos e as experiências relacionadas ao estado de adoecimento e tratamento são, de certa maneira, descartados dos processos de decisão clínica (diagnóstico e terapêutica). Neste modelo, o médico é o detentor do conhecimento necessário para definir os problemas e as melhores formas de tratamento em prol da recuperação clínica, não havendo interesse e nem espaço para ouvir, daqueles que buscam cuidados à saúde, suas expectativas e preferências, isto é, sua experiência com a doença (Serpa Junior et al., 2007).

Mostrando-se como um contraponto à abordagem tradicional, a abordagem da "Narrativa do Adoecimento e do Tratamento" coloca a experiência do sujeito como elemento central, por valorizar a dimensão subjetiva do processo de adoecimento e os seus aspectos relacionais e interpessoais. Esta abordagem reconhece a importância da criação de espaço para que as pessoas falem sobre suas experiências relacionadas ao adoecer, possibilitando, desta forma, a valorização da sua palavra e experiência, permitindo o desenvolvimento de uma relação dialógica entre médicos e pacientes, auxiliando os médicos a compreenderem o significado de "estar doente" para cada indivíduo em particular. Neste cenário, o médico é desafiado a: ampliar suas perspectivas, inserir-se em situações complexas, tornar-se mais exposto, confrontar-se com suas concepções e preconceitos e, consequentemente, repensar suas práticas e decisões clínicas (Serpa Junior et al., 2007).

Alguns fatores, como o declínio dos índices de mortalidade relacionados a doenças infecciosas e o aumento de doenças crônicas e degenerativas, ainda demandam mudanças significativas nas práticas clínicas no que diz respeito à valorização dos sentimentos, experiências e percepções sobre o adoecimento. Como exemplo, pode-se citar o caso de médicos que valorizam a narrativa e a experiência do adoecer e do tratamento dos portadores de doenças crônicas e degenerativas durante o atendimento clínico, para melhor compreenderem como estes lidam com as limitações que comprometem a realização das suas atividades cotidianas (Grossman, Cardoso, 2006).

Um outro fator que vem trazendo transformações na relação entre pacientes e médicos é o aumento no número de pessoas que utilizam a internet para buscar informações sobre problemas de saúde e suas formas de tratamento e prevenção, ocasionado pela maior oferta de conteúdos relacionados à área da saúde devido à evolução das tecnologias digitais, em especial a web 2.0³ (Garbin, Pereira Neto, Guilam, 2008).

As facilidades oferecidas pela web 2.0, no que diz respeito à publicação de conteúdos, ao compartilhamento de informações e às possibilidades de interação, vêm fazendo com que uma parcela significativa de médicos utilize ferramentas digitais para disponibilizar conteúdos relacionados à área da saúde. Além disso, os sujeitos que buscam cuidados à saúde também utilizam essas mesmas ferramentas para expressarem seus sentimentos e suas experiências do "estar doente", para, desta forma, darem significado ao momento conturbado que vivenciam; para compartilhar suas experiências, suas angústias e seus sofrimentos do adoecer com outras pessoas, e para construírem conhecimentos sobre seus problemas de saúde, permitindo se sentirem mais seguros e confiantes durante o tratamento ao qual são submetidos (Manhattan Research, 2007; O'Reilly, 2005).

De acordo com Garbin, Pereira Neto e Guilam (2008), o aumento da oferta de conteúdos relacionados à área da saúde e o maior interesse em buscar informações vêm trazendo mudanças na postura das pessoas durante o atendimento clínico, as

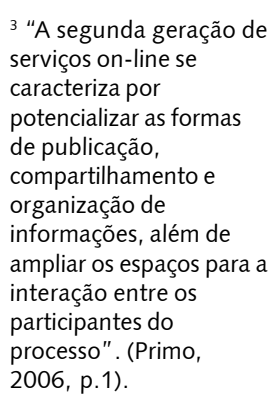

2006, p.1) 
quais adotam uma postura mais crítica diante do diagnóstico e do tratamento sugeridos. Este fato tem levado alguns médicos não somente a se voltarem para as questões referentes ao diagnóstico e ao tratamento das doenças, mas também para as questões referentes à valorização da narrativa daqueles que buscam cuidados à saúde e à compreensão das necessidades cognitivas, sociais e emocionais (Garbin, Pereira Neto, Guilam, 2008).

Neste contexto, torna-se essencial que os cursos de formação médica não somente se preocupem em desenvolver competências e habilidades para lidar com as questões técnicas, mas considerem a importância de preparar os futuros médicos para desenvolverem uma prática clínica baseada em abordagens que valorizem as experiências dos sujeitos, ou seja, a dimensão subjetiva que permeia os processos de adoecimento e tratamento (Serpa Junior et al., 2007; Lampert, 2001).

O desenvolvimento de estratégias pedagógicas, mediadas por ferramentas de informação e comunicação da web 2.0, parece ser um dos possíveis caminhos a serem explorados neste processo. Isto porque a inserção das tecnologias digitais, segundo Struchiner (1998), tem potencialidades para promover mudanças significativas nos modelos educativos.

Diante destas questões, este estudo objetivou discutir as possibilidades de utilização das ferramentas de informação e comunicação da web 2.0 como ferramenta pedagógica nos cursos de formação na área da saúde. Para atender este objetivo, o estudo investigou, com base nos princípios e orientações procedimentais da webometria e da cibermetria (Vanti, 2005), espaços digitais, em especial os weblogs e as comunidades do orkut, que apresentam assuntos relacionados a psicopatologias, objetivando confirmar a existência de artefatos que tenham potencial para serem utilizados como recursos de aprendizagem na disciplina Psicologia Médica. Além disso, foram analisadas as possíveis contribuições desses recursos para o desenvolvimento de atividades educativas que viabilizam a compreensão da subjetividade por meio da valorização da narrativa e do papel dos médicos tanto no contexto da formação quanto da prática, com base na visão de um grupo de professores desta disciplina no curso de Medicina da UFRJ. Os métodos escolhidos para a coleta e análise dessas informações foram, respectivamente, o Grupo Focal e a Análise de Conteúdo (Minayo, 1993).

\section{Uso das ferramentas da web 2.0 no contexto da saúde}

As possibilidades de utilização das ferramentas da web 2.0 na área da saúde, segundo Boulos, Maramba e Wheeler (2005) e McLean, Richards e Wardman (2007), são bastante variadas. Em seus estudos, os autores apontam algumas possibilidades como, por exemplo: a utilização dos weblogs para discussão de casos clínicos, imagens clinicas e tópicos específicos da área médica; e o uso dos softwares sociais para interação e comunicação entre aqueles que buscam cuidados à saúde, seus familiares e equipe médica, como vem ocorrendo, por exemplo, em alguns hospitais universitários nos EUA.

O weblog é um aplicativo da web que permite a inserção de informações, também conhecida como postagens. Essas informações são apresentadas em ordem cronologicamente inversa, isto é, as mais recentes são apresentadas antes das mais antigas. As postagens são constituídas por textos, imagens, vídeos, sons e/ou links. Além disso, existe um recurso denominado "área de comentários", que permite que outras pessoas possam fazer considerações e observações sobre as informações inseridas, favorecendo a interação entre o proprietário do weblog e as pessoas que o visitam e, até mesmo, entre os próprios visitantes (Valente, Mattar, 2007; Boulos, Maramba, Wheeler, 2005).

O software social é um aplicativo da web, que agrega diferentes tipos de ferramentas (fórum, chat, e-mail, recados ou mensagens instantâneas), que possibilita a interação, mediada pela internet, entre pessoas ou grupos de pessoas, e a criação de redes sociais e comunidades que possuem afinidades e interesses comuns, possibilitando o compartilhamento e a discussão de diferentes temáticas. Dentre os inúmeros softwares de relacionamentos existentes, o orkut é, no Brasil, o mais utilizado. Esta popularidade se deve às suas características de inovação tecnológica, que permitem o acesso a milhões de usuários, facilidade de utilização e oferta de inúmeras ferramentas para a comunicação e construção dos perfis dos participantes (Valente, Mattar, 2007; Primo, Brambilla, 2004).

Apesar de compartilharem os princípios da web 2.0, essas ferramentas possuem características que as diferenciam e que, de certa forma, definem suas formas de utilização. No caso do weblog, a sua 
principal característica está voltada para a publicação de informação na internet, que faz com que a ferramenta possa ser utilizada para a construção de espaços de expressão pessoal. No caso do software social, a principal característica é a interação, que faz com que ele seja mais utilizado para criação de comunidades de aprendizagem e estabelecimento de laços sociais (Valente, Mattar, 2007).

A aplicabilidade das ferramentas da web 2.0 no contexto educacional, de acordo com Anderson (2007), possui quatro vertentes: pesquisa acadêmica, publicações, biblioteca e ensino-aprendizagem. No que se refere à pesquisa acadêmica, as ferramentas são utilizadas para: compartilhar, com a comunidade científica, os resultados obtidos nos estudos, difundir informações científicas junto ao público e ajudar os pesquisadores a armazenarem e organizarem os seus documentos acadêmicos. No caso das publicações, elas podem ser utilizadas como um meio mais rápido para a publicação de informações, quando comparadas às mídias tradicionais, tais como livros, revistas e periódicos, e para facilitar o acesso às informações publicadas. Nas bibliotecas, elas podem oferecer novas formas de indexação, que auxiliem a recuperação de informação e coloquem os usuários não somente como consumidores, mas também como produtores de conteúdo. Já no que se refere ao ensinoaprendizagem, o uso das ferramentas possibilita a realização de práticas educativas que valorizam a aprendizagem continuada e o desenvolvimento do espírito criativo e inovador dos alunos. Além disso, contribuem para: o desenvolvimento das habilidades voltadas para a reflexão, a investigação, o autoaprendizado, a negociação, o compartilhamento de ideias e o trabalho colaborativo (Anderson, 2007; Primo, 2006).

O uso dos weblogs e dos softwares sociais no contexto da formação médica possibilita a criação de comunidades de aprendizagem, mediadas por tecnologias digitais, que permite aos alunos realizarem atividades colaborativas e compartilharem recursos e conhecimento. Tais possibilidades podem trazer novas perspectivas para o processo de aprendizagem envolvendo professores, alunos, sujeitos acometidos por patologias e diferentes especialistas. Além disso, essas ferramentas são adequadas para divulgar e transmitir informação relacionada à saúde, servir de apoio a consultas acadêmicas e capacitar profissionais da área da saúde que possuem dificuldades de acesso aos centros acadêmicos e hospitais de referência (McLean, Richards, Wardman, 2007; Boulos, Maramba, Wheeler, 2005).

Mesmo diante das inúmeras contribuições que as ferramentas da web 2.0 oferecem para o processo de aprendizagem, Boulos, Maramba e Wheeler (2005) afirmam ainda que é extremamente necessária a realização de novos estudos que apontem estratégias adequadas para a utilização desses recursos nas práticas educativas nos cursos da área da saúde.

\section{Materiais e métodos}

Nesta primeira etapa da pesquisa, o estudo foi desenvolvido em duas partes. A primeira parte é referente ao levantamento, identificação e classificação dos weblogs e das comunidades do orkut, que apresentam assuntos relacionados a psicopatologias, com objetivo de evidenciar a existência de um repertório de materiais que podem ser utilizados como recursos de aprendizagem na disciplina Psicologia Médica. A segunda parte objetivou analisar, com base na perspectiva de um grupo de docentes da disciplina Psicologia Médica, as contribuições oferecidas por esses recursos no desenvolvimento de estratégias de aprendizagem que valorizem a narrativa e as questões subjetivas que permeiam as práticas médicas. Considerando que alunos são elementos centrais do processo educativo, estudos posteriores levarão em consideração as percepções destes, objetivando ampliar o conhecimento sobre a utilização e o impacto da introdução das ferramentas da web 2.0 em práticas educativas. Além disso, incluirão levantamentos de outras psicopatologias e patologias que também são temáticas relevantes para a Psicologia Médica.

\section{Levantamento, identificação e análise dos weblogs e das comunidades do orkut}

Optou-se por realizar um estudo exploratório dos weblogs e comunidades do orkut que apresentam, como temática, os assuntos relacionados a diferentes psicopatologias, baseados em alguns princípios e 
${ }^{4}$ Motor de busca disponível em: http:// www.google.com.br/ blogsearch?hl=pt-BR

${ }^{5}$ Software socia disponível em: http:// www.orkut.com.br

${ }^{6}$ Títulos e endereços (URL) dos weblogs que foram fornecidos como exemplo para os professores participantes do grupo focal:

"Bipolar... ou Mente poderosa" (http://sfmentepoderosa. blogspot.com) e

"Mais um diário de mais um bipolar" (http://maisumbipolar. blogspot.com)

${ }^{7}$ Títulos e endereços (URL) das comunidades do orkut que foram fornecidos como exemplo para os professores participantes do grupo focal:

"Síndrome do Pânico. Tem cura?" (http:// www.orkut.com.br/ Main\#Community? $\mathrm{cmm}=67689993) \mathrm{e}$ "Síndrome do

Pânico" (http:// www.orkut.com.br/ Main\#Community. aspx? $\mathrm{cmm}=$ 33690625). orientações procedimentais da webometria e da cibermetria, tais como: técnicas de coletas de dados recomendadas, frequência de distribuição e classificação dos espaços. A webometria e a cibermetria são campos de conhecimento que estão relacionados à análise quantitativa dos conteúdos disponibilizados na internet, da estrutura de links, do uso da internet e de suas ferramentas de informação e comunicação (Vanti, 2005).

Para realizar o levantamento dos weblogs, foi utilizado o motor de busca google pesquisa de blogs ${ }^{4}$ e, no caso das comunidades do orkut ${ }^{5}$, foi o próprio motor de busca disponibilizado por este software social. A amostra ficou restrita aos espaços que apresentavam informações em língua portuguesa. Foram utilizados nove termos de busca: doença mental,esquizofrenia, fobia, psicose, psiquiatria, saúde mental, síndrome do pânico, transtorno bipolar e transtorno mental. Para escolha dos termos, foi previamente solicitado, a dois professores do departamento de Psiquiatria e Medicina Legal da Faculdade de Medicina da UFRJ, envolvidos em um projeto de pesquisa sobre narrativas de adoecimento e tratamento, que indicassem termos relacionados às temáticas tratadas nas disciplinas que estavam sob sua responsabilidade.

O levantamento dos espaços ocorreu em um único dia (27 de outubro de 2008). No caso dos weblogs, pesquisou-se aqueles que apresentavam, em seu título, os termos de busca já citados. Para pesquisar no orkut, foram utilizados, primeiro, os filtros de categoria e idioma, restringindo-se às comunidades pertencentes à categoria "Saúde, bem-estar e fitness". Em seguida, buscou-se por aquelas que apresentavam, no título, os termos especificados pelos professores.

Com base nos resultados obtidos, foi realizada a análise individual das informações presentes em cada um dos espaços digitais, com o intuito de se avaliar a adequação ou não destes à proposta da pesquisa. Diante da falta de informação que dificultava a definição dos objetivos de criação e o perfil das pessoas que criaram os espaços pesquisados, foram empregadas duas estratégias para se coletarem essas informações: a primeira foi a análise das postagens dos weblogs e das mensagens presentes nos fóruns de discussão das comunidades; e a segunda foi entrar em contato com os proprietários dos espaços digitais acessados, para se obterem dados que ajudassem a identificar o perfil dos donos e os objetivos que os levaram a criar esses espaços.

\section{Contribuições pedagógicas dos weblogs e do orkut na perspectiva dos professores}

O grupo focal (Minayo, 1993) foi o método escolhido para coleta das informações que indicassem a visão dos professores sobre as possibilidades de utilização dos weblogs e do orkut como ferramentas pedagógicas nos cursos de graduação em medicina. Os participantes do grupo focal foram três professores da disciplina Psicologia Médica, sob responsabilidade do departamento de Psiquiatria e Medicina Legal da Faculdade de Medicina da UFRJ. Dois dos professores eram do sexo feminino e um do masculino, suas faixas etárias variavam entre quarenta e cinquenta anos, e o tempo médio de magistério dos professores era de 13,3 anos. A seleção desses professores se deveu ao fato de a disciplina Psicologia Médica ser um espaço privilegiado em que se oferece ao aluno, durante sua formação, a oportunidade para refletir sobre os aspectos subjetivos que permeiam a prática médica e a relação entre médicos e pacientes (Nogueira-Martins, 2003).

Dias antes do encontro com os professores, foi oferecida uma lista contendo dois weblogs ${ }^{6}$ e duas comunidades presentes no orkut ${ }^{7}$, com temáticas relacionadas às psicopatologias, com o objetivo de familiarizá-los com a estrutura e funcionamento 
dessas ferramentas e permitir que estes tivessem acesso às narrativas apresentadas, possibilitando, desta forma, que adquirissem um conhecimento prévio sobre o assunto, facilitando assim as discussões sobre as possibilidades de uso das ferramentas no processo de aprendizagem. Para a escolha dos recursos, foram adotados os seguintes critérios: espaços mantidos por sujeitos que buscam cuidados à saúde, que veiculavam narrativas das experiências sobre psicopatologias, que se apresentavam em maior número durante o levantamento, e que possuíam a maior quantidade de postagens (weblogs) ou quantidade de membros (comunidades).

Para auxiliar na condução das discussões, foi elaborado um roteiro com questões semiestruturadas relativas aos objetivos da pesquisa. No dia da reunião com os professores, foi solicitado, durante o encontro, que cada um se manifestasse livremente sobre: (a) sua experiência no uso da informática e da internet, tanto no contexto pessoal quanto no profissional e no educacional; (b) suas considerações pessoais sobre a importância das narrativas e da valorização da subjetividade para a formação médica; (c) as estratégias pedagógicas utilizadas em suas aulas para que os alunos tivessem contato com a narrativa e os aspectos subjetivos que permeiam a formação médica; e (d) sobre as possibilidades de uso dos weblogs e das comunidades do orkut na disciplina Psicologia Médica. Como se pode perceber, as questões apresentadas foram abrangentes, extrapolando perguntas pontuais sobre as contribuições dos weblogs e do orkut para o processo de aprendizagem. Entretanto, elas se mostraram essenciais para a compreensão da visão dos docentes sobre de que forma essas ferramentas podem contribuir para a valorização das questões subjetivas e da narrativa na formação médica e nas práticas clínicas, suas práticas de ensino e a utilização das Tecnologias de Informação e Comunicação (TICs) na educação. As falas e debates dos professores foram gravados, com devido consentimento, e, posteriormente, transcritos e analisados com base no método de Análise do Conteúdo (Minayo, 1993).

\section{Resultados}

\section{Análise dos resultados do levantamento dos weblogs e do orkut}

Os resultados obtidos durante o levantamento revelaram um total de 190 weblogs e 362 comunidades do orkut. Destes, somente 64 blogs e 187 comunidades foram consideradas válidas para o presente estudo, já que, após um exame minucioso, estes foram considerados como vinculados às temáticas pesquisadas. Foram excluídos aqueles espaços que: (a) não possuíam relação com as temáticas já citadas, (b) não apresentavam endereço (URL) válido, e (c) não apresentavam as datas das postagens ou não possuíam nenhuma postagem.

A análise dos dados coletados indicou que, dos 78 weblogs analisados, 25,64\% (20) deles foram criados por profissionais da área da Saúde; $23,08 \%$ (18) por pessoas acometidas por psicopatologias; $17,95 \%$ (14) por instituições que atuam na área da Saúde; 10,26\% (8) por estudantes; 5,13\% (4) por professores da área da Saúde, e 2,56\% (2) por familiares de pessoas acometidas por psicopatologias. Já no caso das comunidades do orkut, percebeu-se que 33,69\% (63) delas foram criadas por pessoas acometidas por psicopatologias; $24,06 \%$ (45) por profissionais da área da Saúde; 9,09\% (17) por instituições que atuam na área da Saúde; 4,28\% (8) por familiares de pessoas acometidas por psicopatologias; $1,07 \%$ (2) por estudantes, e 0,53\% (1) por professores da área da Saúde. Cabe destacar que não foi possível identificar o perfil das pessoas que criaram os espaços digitais em 15,38\% (12) weblogs e em $27,28 \%$ (51) comunidades pesquisadas (Figura 1). 


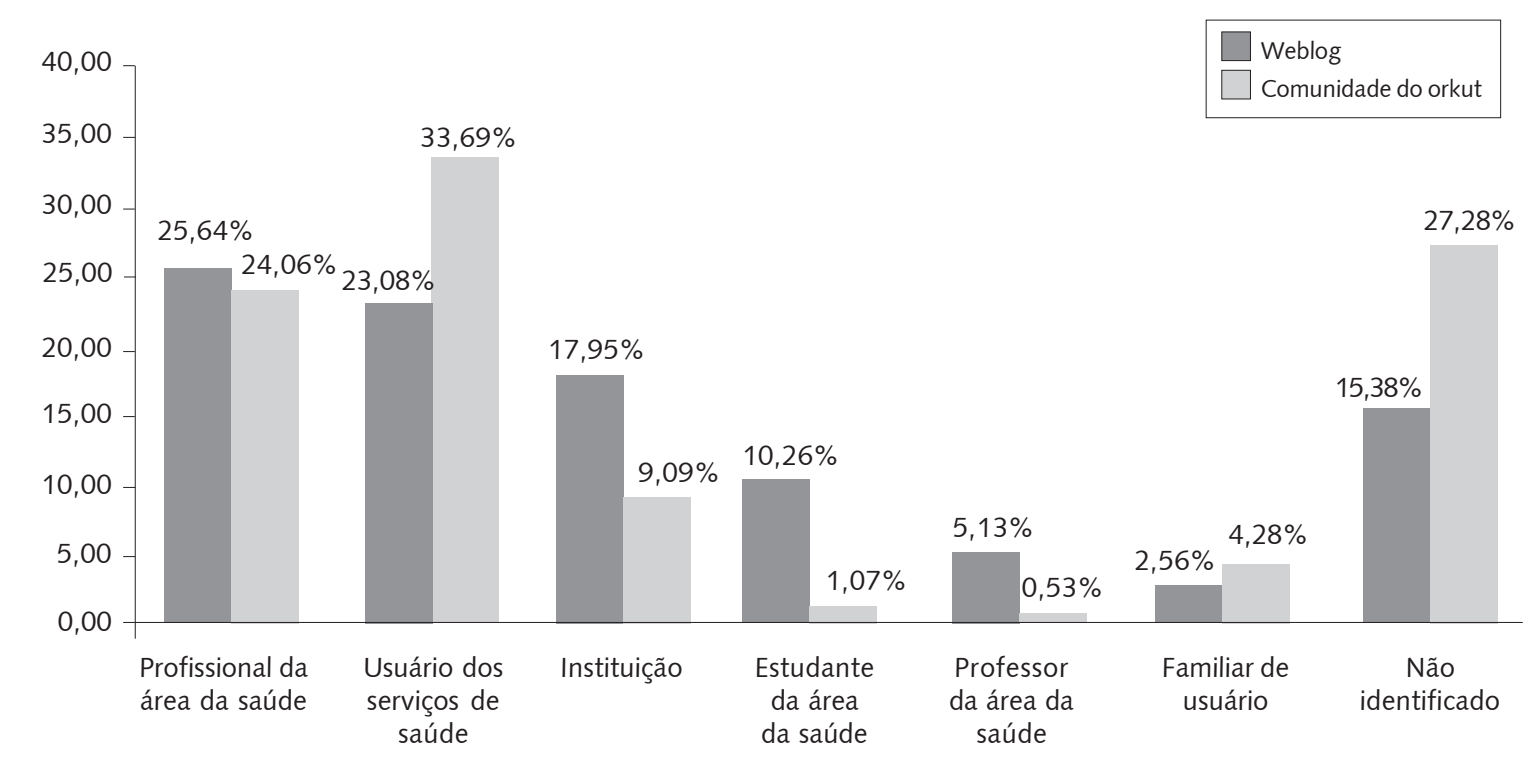

Figura 1. Perfil dos proprietários dos weblogs e das comunidades do orkut.

Os resultados mostram a maior presença de espaços mantidos por pessoas acometidas por psicopatologias e profissionais da área da saúde. Essas informações corroboram os achados de alguns autores, como Manhattan Research (2007) e Garbin, Pereira Neto e Guilam (2008), sobre o aumento do interesse de médicos em veicular informação sobre saúde na internet e novas possibilidades de interação daqueles que buscam cuidados à saúde, objetivando a troca de informação sobre as patologias e formas de tratamentos; e, ainda, a busca por espaços que permitam a expressão dos seus sentimentos, angústias, medos e experiências sobre o adoecer. Em contrapartida, os resultados indicam que o número de espaços mantido por professores é bastante reduzido, tal fato deve-se, provavelmente, à falta de conhecimento e familiaridade dos docentes com o manuseio das ferramentas da web 2.0.

O estudo também mostrou que $52,56 \%$ (41) dos weblogs analisados tinham, como principal objetivo, a apresentação de informações sobre as psicopatologias; 19,23\% (15) a veiculação de narrativas de experiências relacionadas ao processo de adoecimento e tratamento; $12,82 \%$ (dez) o desenvolvimento de atividades educativas, e 11,54\% (nove) a divulgação de serviços prestados na área da Saúde. Já com relação às comunidades, percebeu-se que 42,25\% (79) delas foram criadas exclusivamente para apresentar informações sobre as psicopatologias; $26,74 \%$ (cinquenta) para divulgar simultaneamente informações sobre as psicopatologias e narrativas sobre a experiência do processo de adoecimento e tratamento; 17,65\% (33) para veicular exclusivamente as narrativas das experiências relacionadas ao adoecer; 9,62\% (18) para divulgar serviços prestados na área da Saúde, e 1,07\% (dois) para o desenvolvimento de atividades educacionais. É necessário destacar que não foi possível identificar os objetivos de criação em 3,85\% (três) weblogs e em 2,67\% (cinco) comunidades analisadas (Figura 2). 


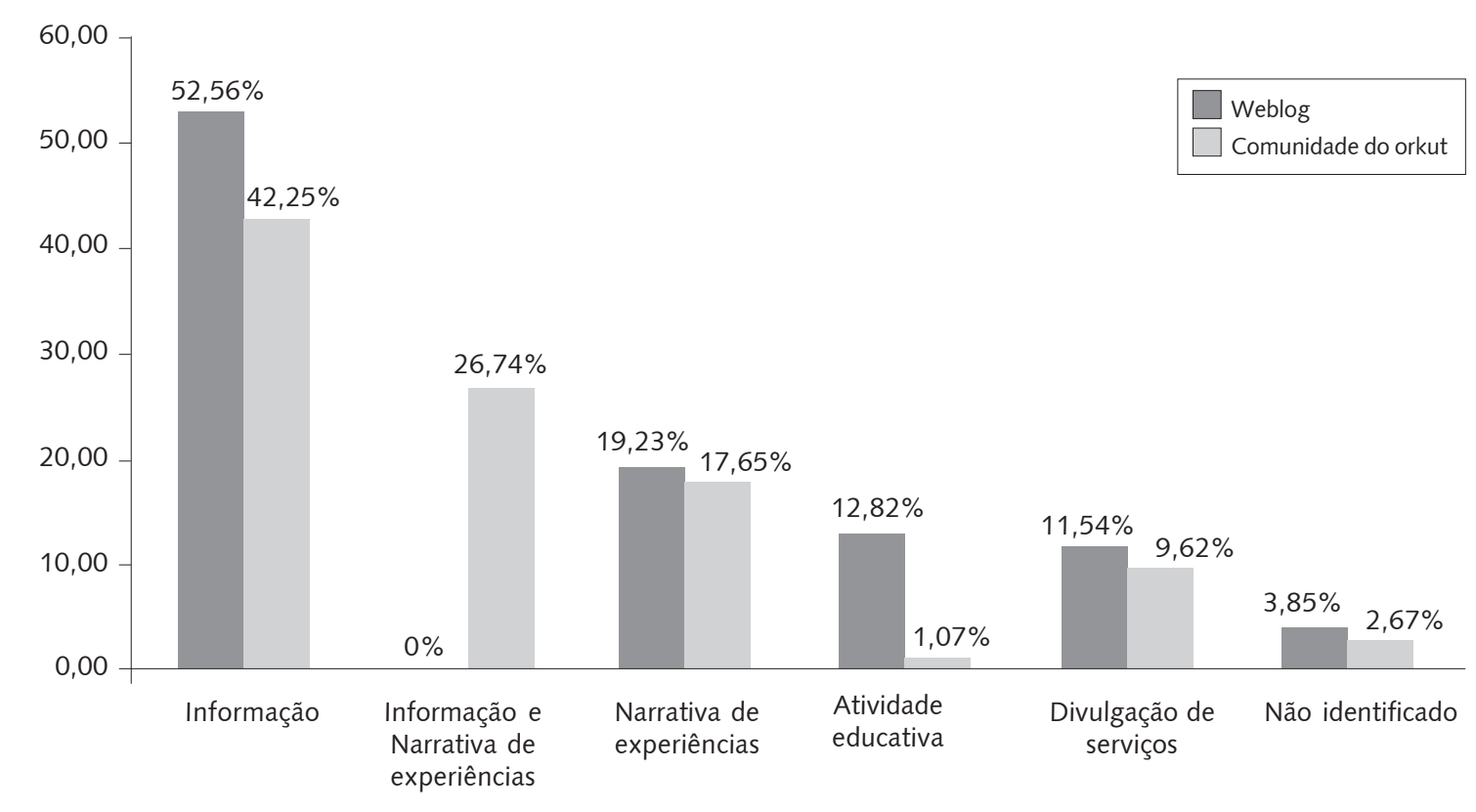

Figura 2. Objetivo de criação dos weblogs e das comunidades do orkut.

A presença significativa de weblogs e comunidades com o objetivo de apresentar informação sobre as psicopatologias pode ser um indicador positivo da possibilidade de uso desses recursos como repositórios de informação em atividades pedagógicas, que podem ser utilizados não somente como fonte de conhecimento técnico, mas também como outros espaços que possibilitem a análise das narrativas para a observação dos aspectos subjetivos que permeiam o processo de adoecimento e tratamento.

Ainda é possível observar a existência de um número significativo de espaços digitais voltados para a veiculação de experiências, sensações e angústias sobre o adoecimento. Mesmo que esses espaços não tenham sido concebidos exclusivamente para atender um propósito educacional, eles podem ser utilizados no desenvolvimento de atividades que promovam novas formas de acesso às experiências subjetivas do processo de adoecer, favorecendo a reflexão e a sensibilização dos alunos sobre a importância da valorização da narrativa e da subjetividade na prática médica.

\section{Análise dos resultados sobre as contribuições pedagógicas dos weblogs e do orkut}

Com base na análise das verbalizações coletadas no grupo focal, foi possível identificar cinco núcleos temáticos nas discussões ocorridas no grupo focal: (1) relação entre prática médica e subjetividade, (2) relação entre formação médica e subjetividade, (3) estratégias pedagógicas utilizadas, (4) possibilidades de uso dos weblogs e do orkut, e (5) aspectos positivos e negativos relacionados ao uso das tecnologias no ensino médico. Como se pode perceber, as falas dos professores foram abrangentes, extrapolando questionamentos pontuais sobre as contribuições das ferramentas para o processo de aprendizagem. Os núcleos temáticos possibilitaram compreender a visão dos docentes sobre o uso das ferramentas da web 2.0 no contexto de suas práticas educativas, da formação médica e do atendimento à saúde. 


\section{1) Relação entre prática médica e subjetividade}

Os resultados indicaram que, sendo a prática médica uma relação que envolve seres humanos (médicos e pacientes), é quase, ou até mesmo, impossível desassociar a subjetividade do exercício da Medicina, já que os sentimentos, as sensações e as experiências vivenciadas fazem parte de todas as relações humanas (Silva, Rocha, 2008).

"[...] acho muito importante a noção de que o médico também é humano [...]. Tem alguns casos, que a gente se identifica demais, que é difícil, entende? Que a gente vira poste, encaminha para outro médico e até chora [...]. Quando a gente chora e faz cafuné [...]. Quando a gente não devia ter essa atitude [...]. Mas isso não devia ser a regra, a gente tem que buscar um equilíbrio". (fala do professor A)

Na perspectiva destes professores, diferentes fatores podem dificultar a abertura de espaços e momentos para se trabalhar a questão da subjetividade na Medicina. Dentre eles, pode-se citar a exigência de maior disponibilidade de tempo e demanda emocional por parte dos médicos a fim de lidarem com essas questões durante o atendimento, além da necessidade de criação de artifícios com o objetivo de preservarem a sua saúde psíquica e emocional, diante de situações vivenciadas durante o acompanhamento daqueles que buscam cuidados à saúde (Silva, Rocha, 2008; Nogueira-Martins, 2003).

“[...] há uns 15 dias, duas alunas me perguntaram como é que elas faziam para ficar menos tristes com os casos que estavam vendo nas enfermarias. Daí eu respondi: Não tem como ficar menos triste [...]. Disse que era uma escolha pessoal, que tinham que ver qual era o modelo para elas de boa prática médica, que realmente se envolver é muito difícil sim, que a tendência da gente é virar poste [...]. Mas talvez, entre virar poste, e aquele que chora a toda a hora, faz carinho, passa a mão na cabeça [do paciente] [...]. Tem aí um meio termo que você consegue. (fala do professor $\mathrm{C}$ )

\section{2) Relação entre formação médica e subjetividade}

Para atender as demandas da prática médica, de acordo com as falas dos professores, a formação está voltada para o desenvolvimento de competências e habilidades que possibilitem aos alunos lidarem com os aspectos físicos do adoecer e as formas de tratamento das patologias, e não com os aspectos subjetivos do processo de adoecimento.

\footnotetext{
“Nós falamos desse negócio da inserção da subjetividade no campo da medicina [...]. Se isso é possível ou não, é uma questão complicada [...] a questão é como incluir, dentro desse modelo médico hegemônico, algo que diz respeito ao sofrimento, angústia e dor. O médico é treinado a estudar a lesão, a encontrar a doença. O curso médico é para isso. É assim que os livros ensinam os alunos[...]. Por isso, a Medicina, metodologicamente e epistemologicamente, precisa ser como o conhecimento científico e não tem como ser de outro jeito [...]". (fala do professor B)
}

Eles destacaram que poucos são os momentos reservados para a discussão das questões referentes à vivência, aos sentimentos e às experiências tanto de sujeitos que buscam cuidados à saúde quanto dos futuros médicos durante a formação e a prática médica (Silva, Rocha, 2008). É importante ressaltar que a fala do professor apresenta dilemas que não podem ser ignorados: a questão da relação entre conhecimento científico e subjetivo na prática e na formação médica. O conhecimento científico não pode ser colocado em segundo plano durante formação, pois irá comprometer a atuação no exercício profissional. Entretanto, a subjetividade estará sempre presente, já que esse aspecto é inerente a todas as áreas que envolvem seres humanos e, por isso, não teria por que ser diferente na área da Saúde.

Normalmente, a disciplina Psicologia Médica se revela um momento privilegiado, durante todo o curso de Medicina, para a discussão dessas questões, tentando contribuir efetivamente para a formação de médicos mais sensibilizados às questões referentes à valorização dos aspectos subjetivos e da narrativa durante a prática médica (Nogueira-Martins, 2003). 
“Você vai chegar no paciente e ele vai ser melhor tratado, por um aluno mais sensível, um médico melhor, mais bem informado [...]". (fala do professor $\mathrm{C}$ )

\title{
3) Estratégias pedagógicas utilizadas
}

A análise dos resultados mostrou que estes professores fazem uso de diferentes estratégias pedagógicas para tratar da valorização da narrativa sobre o processo de adoecimento e de tratamento, sempre com o objetivo de levar os alunos a questionarem e a refletirem sobre os aspectos referentes a sentimentos, expectativas, sensações e emoções que permeiam a prática médica, tanto do ponto de vista dos próprios médicos quanto daqueles que buscam cuidados à saúde. Dentre as estratégias mais citadas, encontram-se: leitura de textos fictícios, apresentação de relatos, realização de debates, apresentação de casos clínicos e exibição de filmes.

\begin{abstract}
"[...] existem filmes ótimos como "Mar aberto" e "O escafandro e a borboleta" que apresentam muitas questões para discussão. Acho que isso gera uma coisa interessante para os alunos [...]. No momento que estão vendo o filme ou uma peça de teatro imbuídos do papel de médico, aquilo entra de outra maneira [...]. Já quando vai um paciente falar na sala de aula da sua experiência como doente, os alunos não precisam entrevistá-los, eles não são médicos naquele momento. Aquilo causa um impacto emocional mais forte [...]. Mas, além de tudo isso, o que eu acho que funciona mesmo é a discussão de casos em que os alunos falam da sua experiência. Além do ofício médico, da aprendizagem, da técnica, da habilidade [...]. Eles falarem como é complicado para acompanharem pacientes todos os dias... As pessoas internadas no HU são pacientes muito graves, o que gera uma exigência emocional muito grande. É um trabalho muito difícil, muito delicado para qualquer pessoa, ainda mais com 20 e 21 anos de idade [...]". (fala do Professor B)
\end{abstract}

\section{4) Possibilidades do uso dos weblogs e do orkut}

Em um contexto mais abrangente, segundo a visão desses professores, a utilização das ferramentas da web 2.0 pode trazer contribuições significativas para o processo de aprendizagem, pois a inserção das tecnologias no ambiente educacional permite o engajamento dos alunos na realização das atividades, os torna mais participativos e favorece a aproximação entre alunos e professores (Kenski, 2007).

“O Professor B sugeriu usarmos mais audiovisual e propormos que os alunos apresentem os trabalhos no final da disciplina utilizando fragmentos de filmes [...]. É impressionante como os alunos começaram a gostar mais do trabalho [...]". (professor A)

No que diz respeito ao uso dos weblogs e do orkut para o desenvolvimento de estratégias pedagógicas, com a finalidade de tratar as questões relacionadas à subjetividade, foram apresentadas duas propostas: (a) uso dos weblogs e das comunidades como repositório de informações (Gomes, Lopes, 2007), em que os espaços já existentes na internet poderiam ser utilizados pelos alunos como fonte de informação e consulta para realização de atividades e para complementar os assuntos tratados nas aulas; (b) criação de espaços que possibilitem alunos e professores discutirem sobre temáticas, trocarem informações e aprofundarem os assuntos tratados durante as aulas, permitindo novas oportunidades de compartilhamento de experiências, vivências e sentimentos, suscitados pelo contato com as pessoas que buscam cuidados à saúde, ao longo da formação médica (Forte, Rocha, 2007; Recuero, 2007).

"Cada grupo de alunos escolhe um tema sobre qual eles querem trabalhar: eutanásia, câncer de mama, vocação médica e anorexia [...] os weblogs e as comunidades do orkut podem ser usados como bibliografias dos trabalhos dos alunos [...]". (professor B)

"No caso do orkut, seria interessante criar uma comunidade para discutir tópicos de Psicologia Médica [...]. Até mesmo a criação de uma comunidade que fosse um espaço que permitisse aos alunos trocar experiências entre eles de forma mais tranqüila [...]". (professor C) 
Segundo os professores, as narrativas sobre o processo de adoecimento, apresentadas nos weblogs e nas comunidades, são mais espontâneas e próximas da realidade vivenciada do que aquelas apresentadas nos textos fictícios, livros biográficos e filmes.

\footnotetext{
"Tem alguns exemplos que nós falamos da outra vez, como os livros autobiográficos de pessoas". (professor A)

"Mas eu tenho a impressão que nos weblogs e nas comunidades do orkut a coisa mais viva do que o livro. Porque o livro já é um processo de reflexão [...]. Uma coisa mais romanceada". (professor C)
}

As observações apresentadas pelos professores sobre o potencial do uso dos espaços digitais para o desenvolvimento de atividades, juntamente com os resultados do levantamento realizado neste estudo, podem ser compreendidos como indicadores favoráveis para a utilização dos weblogs e do orkut no contexto educacional, para disponibilizar informações sobre as psicopatologias e para criar novas formas de aproximação dos alunos com diferentes experiências vivenciadas durante o adoecer, favorecendo a reflexão e a sensibilização sobre a importância da valorização da narrativa e da subjetividade na prática médica. Destaca-se que, apesar de os professores reconhecerem o diferencial das narrativas presentes nesses espaços, eles não cogitaram a possibilidade de seu uso para o desenvolvimento de atividades que permitam a análise das narrativas para a observação dos aspectos subjetivos que permeiam o processo de adoecimento e tratamentos.

\section{5) Aspectos positivos e negativos relacionados ao uso das tecnologias no ensino médico}

Diferentes aspectos, de acordo com os professores, podem favorecer a inserção do weblog e do orkut como recursos de aprendizagem nos cursos de formação médica. Dentre esses, destacaram-se: o interesse, o domínio e a familiaridade sobre o uso das ferramentas digitais pelos alunos.
"O Professor B sugeriu de usarmos mais audiovisual e propormos que os alunos apresentem os trabalhos no final da disciplina utilizando fragmentos de filmes [...] Os alunos pegam os filmes pela internet, fazem a edição e produzem um novo material [...]. Eles próprios usam a cena do filme para discutir a teoria". (professor A)

Além disso, foram identificados desafios que devem ser superados para que se possa ter o uso efetivo dessas ferramentas no ambiente educacional, como: a falta de interesse, conhecimento e familiaridade dos recursos tecnológicos dos professores, as dificuldades para o manuseio das ferramentas que, consequentemente, levam à inibição do uso efetivo e ao receio de que a inserção das tecnologias venha substituir as estratégias tradicionalmente utilizadas e o contato face a face com os alunos.

\footnotetext{
"Eu tenho que confessar que eu sou um pouco alérgica a essas coisas [orkut, weblogs e MSN] porque você perde muito tempo". (professor A)

"Se a gente está tratando de humanização, e humanização implica em sensorialidade, em cheiro e ir com a cara do outro. Tem que bater com o santo, tem que cruzar o santo ou não cruzar o santo. Como é que se cruza santo via internet? [...] Como é que vai com a cara do outro, ou não vai? [...] como é que a gente vai utilizar, se é que é o caso, um sistema como esse, para facilitar o ensino, para fortalecer o ensino, para que o estudante perceba que ele e os doentes são gente [...]. Isso não é uma contradição?" (fala do professor B)
}

Ressalta-se que estes desafios não estão restritos ao contexto da Educação em Saúde e das ferramentas de comunicação da web 2.0, já que diversos estudos apontam que esses são desafios presentes em todos os níveis educacionais (Ferreira, Ventura, 2008; Tonani, 2008; Kesnki, 2007). Isto é, indicam a necessidade de maior aprofundamento sobre estes ambientes oferecidos pelas TICs, como novos espaços sociais que não substituem o contato presencial, mas que podem enriquecer a experiência dos alunos na formação médica. 


\section{Considerações finais}

Os resultados do levantamento dos espaços digitais e da análise das percepções dos professores sobre as contribuições dos weblogs e do orkut ao processo de aprendizagem permitiram constatar que diferentes profissionais da área da saúde estão utilizando essas ferramentas como um instrumento para veicular informação sobre psicopatologias. Além disso, percebeu-se que as pessoas tendem a utilizar esses espaços como mais um meio para buscar informações sobre a doença, para expressar seus sentimentos e suas experiências com o processo de adoecimento e para compartilhar suas angústias e sofrimentos com outras pessoas que também estão vivenciando este mesmo momento.

No que se refere ao processo de aprendizagem, percebeu-se que os blogs e o orkut ainda são poucos utilizados no contexto da formação na área da saúde. Apesar disso, foi constatado, segundo a percepção dos docentes que participaram deste estudo, que eles podem ser utilizados como ferramentas pedagógicas para o desenvolvimento de estratégias que permitam aos alunos e professores discutirem sobre a importância da valorização da subjetividade tanto na formação quanto na prática profissional. Eles também podem ser usados com uma nova forma de aproximação dos alunos com as experiências relacionadas ao processo de adoecimento e tratamento, por meio das narrativas apresentadas nestes espaços. Além disso, podem servir como mais uma fonte de informação a ser utilizada para o desenvolvimento dos trabalhos e atividades.

A análise das verbalizações mostrou que os professores participantes apresentam posicionamento ambíguo com relação ao uso das novas tecnologias de informação e comunicação no contexto educacional. Apesar de reconhecerem as possibilidades e as contribuições da inserção de weblogs e comunidades do orkut no processo de aprendizagem, eles acreditam que as relações interpessoais mediadas pelas tecnologias digitais apresentam limitações na contemplação dos aspectos sensoriais, afetivos e emocionais. Diante disso, torna-se interessante o desenvolvimento de um trabalho junto a esses docentes para auxiliá-los na familiarização com as ferramentas da web 2.0, em especial o weblog e o orkut, objetivando a utilização desses recursos no contexto educacional (Moran, 2000). Isto possibilitará a esses professores vivenciarem situações e construírem relações, por meio desses espaços, permitindo que repensem seus pontos de vista sobre as limitações das ferramentas da internet para a valorização dos aspectos subjetivos.

Torna-se importante frisar que a utilização das ferramentas da web 2.0 como um simples recurso didático não oferece garantias de que estas contribuirão de forma significativa para o processo de aprendizagem, no que se refere à importância da valorização da subjetividade durante a prática profissional. O uso de novos recursos por si só ou de uma forma isolada não é suficiente para as mudanças necessárias, e as estratégias pedagógicas propostas devem ir além da simples reprodução de conteúdos. É necessário o desenvolvimento de atividades que contemplem a solução de problemas, a realização de tarefas contextualizadas e que permitam ao aluno assumir papel ativo no processo de construção do conhecimento, favorecendo, assim, transformações substanciais do modelo de relação entre profissionais da área da saúde e paciente, atualmente adotado, para um modelo que valorize tanto os aspectos físicos quanto os aspectos subjetivos do adoecimento. Diante disso, as diferentes ferramentas da web 2.0 oferecem potencial para tais práticas educativas, já que elas podem ser utilizadas nas atividades pedagógicas tanto como repositórios de conteúdos, quanto como espaços de interação e colaboração.

Os resultados estão restritos ao universo pontual desta pesquisa, já que apresentam a percepção dos docentes participantes sobre as contribuições do uso pedagógico dos weblogs e das comunidades do orkut. Já que esses professores, por causa da natureza da disciplina Psicologia Médica, possuem normalmente uma maior aproximação com os aspectos sensoriais, afetivos e emocionais dos sujeitos que buscam cuidados à saúde e dos médicos do que os professores das outras disciplinas que compõem as matrizes curriculares do curso de graduação em Medicina e de outros cursos na área da saúde. Diante disso, para avançar neste campo de investigação, são necessários: a ampliação desta pesquisa para englobar a visão de professores de outros cursos da área da saúde, o uso de outras ferramentas de comunicação da web 2.0 e a viabilização de estudos que envolvam experiências concretas com o uso destes recursos no processo de formação dos profissionais da saúde. 


\section{Colaboradores}

Fabio Maia realizou a coleta dos dados, análise e discussão dos resultados, escrita e formatação do texto. Miriam Struchiner orientou todas as etapas do estudo.

\section{Referências}

ANDERSON, P. What is web 2.0? Ideas, technologies and implications for education. JISC Tech. Stand. Watch, fev. 2007. Disponível em: <http://www.jisc.ac.uk/media/documents/ techwatch/tsw0701b.pdf>. Acesso em: 23 ago. 2007.

BOULOS, M.N.; MARAMBA, I.; WHEELER, S. Wikis, blogs and podcasts: a new generation of Web-based tools for virtual collaborative clinical practice and education. BMC Med. Educ., v.6, n.41, p.1-8, 2005.

EMIG, J. Embodied learning. Engl. Educ., v.33, n.4, p.271-80, 2001.

FERREIRA, A.A.; VENTURA, P.C.S. Concepções de professores acerca da informática educacional. In: SEMINÁRIO NACIONAL DE EDUCAÇÃO PROFISSIONAL E TECNOLÓGICA, 1., 2008, Belo Horizonte. Anais... Disponível em < http:// www.senept.cefetmg.br/galerias/Arquivos_senept/anais/terca_tema5/ TerxaTema5Artigo1.pdf>. Acesso em: 25 jun. 2009.

FORTE, G.M.S.; ROCHA, S.S.D. Quem você conhece? Discutindo as possibilidades pedagógicas do orkut. ETD - Educ. Temat. Dig., v.9, n.1, p.69-83, 2007.

GARBIN, H.B.R.; PEREIRA NETO, A.F.; GUILAM, M.C.R. A internet, o paciente expert e a prática médica: uma análise bibliográfica. Interface - Comunic., Saude, Educ., v.12, n.26, p.579-88, 2008.

GOMES, M.J.; LOPES, A.M. Blogues escolares: quando, como e porquê? In: CONFERÊNCIA WEBLOGS NA EDUCAÇÃO - 3 TESTEMUNHOS, 3 EXPERIÊNCIAS, 2007, Setúbal. Actas... Setúbal, 2007. Disponível em: <http://repositorium.sdum.uminho.pt/bitstream/1822/ 6487/1/gomes2007.pdf>. Acesso em: 15 mar. 2008.

GROSSMAN, E.; CARDOSO, M.H.C.A. As narrativas em medicina: contribuições à prática clínica e ao ensino médico. Rev. Bras. Educ. Med., v.30, n.1, p.6-14, 2006.

KENSKI, V.M. Educação e tecnologias: o novo ritmo da informação. Campinas: Papirus, 2007.

LAMPERT, J.B. Currículo de graduação e o contexto da formação do médico. Rev. Bras. Educ. Med., v.25, n.1, p.7-19, 2001.

MANHATTAN RESEARCH. LLC. Physicians and web 2.0: 5 things you should know about the evolving online landscape for physicians, 2007. Disponível em: <http:// www.manhattanresearch.com/TTPWhitePaper.aspx>. Acesso em: 1 maio 2009.

MCLEAN, R.; RICHARDS, B. H.; WARDMAN, J.I. The effect of web 2.0 on the future of medical practice and education: darwikinian evolution or folksonomic revolution? Med. J. Austr., v.187, n.3, p.174-7, 2007.

MINAYO, M.C.S. O desafio do conhecimento: pesquisa qualitativa em saúde. 2.ed. São Paulo: Hucitec, 1993.

MORAN, J.M. Ensino e aprendizagem inovadores com tecnologias audiovisuais e telemáticas. In: MORAN, J. M.; MASETTO, M.T.; BEHRENS, M.A. (Org.). Novas tecnologias e mediação pedagógica. Campinas: Papirus, 2000. p.11-65.

NOGUEIRA-MARTINS, L.A. Saúde mental dos profissionais de saúde. Rev. Bras. Med. Trabalho, v.1, n.1, p.56-68, 2003.

O'REILLY, T. What is web 2.0. O'Reilly Media, 2005. Disponível em: <http:// www.oreillynet.com/pub/a/oreilly/tim/news/2005/09/30/what-is-web-20.html>. Acesso em: 20 jul. 2007. 
PRIMO, A. O aspecto relacional das interações na web 2.0. In: INTERCOM 2006 - CONGRESSO BRASILEIRO DE CIÊNCIAS DA COMUNICAÇÃO, 29., 2006, Brasília. Anais... Brasília, 2006. Disponível em: <http://www.intercom.org.br/papers/ nacionais/2006/resumos\% 5CR1916-1.pdf>. Acesso em: 23 nov. 2007.

PRIMO, A.; BRAMBILLA, A.M. Software social e construção do conhecimento. In: INTERCOM 2004 - CONGRESSO BRASILEIRO DE CIÊNCIAS DA COMUNICAÇÃO, 27., 2004, Porto Alegre. Anais... Porto Alegre, 2004. Disponível em: <http:// www.intercom.org.br/papers/nacionais/2005/errata/Primo_Brambilla_2004_51.pdf >. Acesso em: 10 abr. 2009.

RECUERO, R.C. O orkut como formador de novas identidades no ciberespaço. In: INTERCOM 2007 - CONGRESSO BRASILEIRO DE CIÊNCIAS DA COMUNICAÇÃO, 30., 2007, Santos. Anais... Santos, 2007. Disponível em: <http://www.intercom.org.br/ papers/nacionais/2007/resumos/R0796-1.pdf>. Acesso em: 10 abr. 2009.

SERPA JUNIOR, O.D. et al. A inclusão da subjetividade no ensino da Psicopatologia. Interface - Comunic., Saude, Educ., v.11, n.22, p.207-22, 2007.

SILVA, P.R.M.; ROCHA, M.S. O ato médico e a subjetividade. Rev. Latinoam. Psicopatol. Fundam., v.11, n.1, p.69-81, 2008.

STRUCHINER, M. Teorias e tendências pedagógicas: implicações para a formulação de programas de formação de recursos humanos na área da saúde. Desenvolvimento de material didático ou instrucional - Oficina de Planejamento do Programa de EAD. Rio de Janeiro: UFRJ/NUTES, 1998.

TONANI, R.L. A percepção do professor acerca do uso da informática educacional no ensino de fisioterapia. In: SEMINÁRIO NACIONAL DE EDUCAÇÃO PROFISSIONAL E TECNOLÓGICA, 1., 2008, Belo Horizonte. Anais... Belo Horizonte, 2008. Disponível em: <http://www.senept.cefetmg.br/galerias/Arquivos_senept/anais/terca_tema5/ TerxaTema5Artigo16.pdf >. Acesso em: 25 jun. 2009.

VALENTE, C.; MATTAR, J. Second life e web 2.0 na educação: o potencial revolucionário das novas tecnologias. São Paulo: Novatec, 2007.

VANTI, N.A.P. Os links e os estudos webométricos. Cienc. Inform., v.34, n.1, p.78-88, 2005.

MAIA, F.; STRUCHINER, M. Utilización de los weblogs y de comunidades del orkut como herramientas pedagógicas en cursos del área de la salud. Interface - Comunic., Saude, Educ., v.14, n.35, p.905-18, out./dez. 2010.

Este artículo discute posibilidades de uso pedagógico de las herramientas de la Web 2.0 en cursos en el área de la salud. Se ha realizado una investigación para evidenciar la existencia de weblogs y de comunidades del orkut que podrían utilizarse como aprendizaje. Se ha hecho un estudio con un grupo de profesores de la disciplina Psicología Médica para analizar las contribuciones de tales herramientas al desarrollo de estrategias pedagógicas. Los resultados demuestran su potencial como recursos pedagógicos con diferentes propuestas de uso en la formación médica; así como también aspectos positivos y negativos para el proceso educacional. En fin se concluye que el uso de estas herramientas favorece el desarrollo de actividades que valoricen la subjetividad en la práctica médica, permitiendo nuevas formas de aproximación a los alumnos con las experiencias del enfermar.

Palabras clave: Software social. Blogs. Tecnologia educacional. Educación médica. 